\title{
Letters
}

Website: www.bmj.com

Email: letters@bmj.com

\section{World Bank must do more to develop safe and sustainable transportation systems}

EDITOR-In examinations of the World Bank's role in international health its influence on the development of transportation systems must not be overlooked. ${ }^{1}$ Each year about one million people die in road traffic accidents, with perhaps 10 million permanently disabled. ${ }^{2}$ And for most of the world the epidemic of road deaths and injuries is just beginning. It is estimated that by 2020 road traffic accidents will be the third leading cause of disability adjusted life years lost worldwide and the second leading cause in the demographically developing countries. $^{3}$

The extent of the carnage will depend heavily on the type of transportation infrastructure the bank promotes. The importance of bank policy on transportation is underscored by the fact that $13 \%$ of lending is for transportation compared with $11 \%$ for health, nutrition, and population. ${ }^{1}$

Close to $80 \%$ of the world's cars are owned and produced by the $15 \%$ of the world's population who live in North America, western Europe, and Japan. The same countries hold the greatest voting power at the bank, which may not bode well

\section{Advice to authors}

We prefer to receive all responses electronically, sent either directly to our website or to the editorial office as email or on a disk. Processing your letter will be delayed unless it arrives in an electronic form.

We are now posting all direct submissions to our website within 72 hours of receipt and our intention is to post all other electronic submissions there as well. All responses will be eligible for publication in the paper journal.

Responses should be under 400 words and relate to articles published in the preceding month. They should include $\leqslant 5$ references, in the Vancouver style, including one to the BMJ article to which they relate. We welcome illustrations.

Please supply each author's current appointment and full address, and a phone or fax number or email address for the corresponding author. We ask authors to declare any competing interest. Please send a stamped addressed envelope if you would like to know whether your letter has been accepted or rejected.

Letters will be edited and may be shortened.

www.bmj.com

letters@bmj.com for the development of safe and sustainable transportation systems. For example, China with its millions of bicycles has one of the most equitable and sustainable transportation systems on the planet. ${ }^{4}$ With European and North American car markets reaching saturation point, however, car manufacturers are looking east. The epidemic of road deaths in China has yet to begin, but already an estimated 29000 children are killed on the roads each year. ${ }^{2}$

The midwife to this new epidemic may well turn out to be the World Bank itself, by conflating motorisation and development and failing to count the true cost of car travel. The neglect of road trauma by the World Health Organisation, and the fact that global funding for research into road safety is lower than that for almost any other cause of human misery, will do nothing to help.

Ian Roberts Director

Child Health Monitoring Unit, Department of

Epidemiology and Public Health, Institute of Child Health, London WC1N 1EH

Ian.Roberts@ich.ucl.ac.uk

1 Abbasi K. The World Bank and world health: Changing sides. BMJ 1999;318:865-9. (27 March.)

2 Murray CJL, Lopez AD. Global health statistics: compendium of incidence, prevalence and mortality estimates for over 200 conditions. Harvard School of Public Health, Boston: Harvard University Press, 1996.

3 Murray CJL, Lopez AD. Alternative projections of mortality and disability by cause 1990-2020: global burden of disease study. Lancet 1997;349:1498-504

4 Roberts I. Letter from Chengdu: China takes to the roads. BMJ 1995;310:1311-3.

\section{The paradoxes of genetically modified foods}

\section{Protection of the public health should underpin all decisions}

EDITOR-In his editorial on genetically modified foods Dixon eschews certain important issues. ${ }^{1}$

Firstly, he does not point out that, although scientists claim this technology will help to feed the world's burgeoning population, food production is not the problem. There are enough natural resources for us all to be fed: inequity of food distribution results in the starvation of millions in poorer nations.

Secondly, he dismisses the campaigners who draw parallels between bovine spongiform encephalopathy and genetically modified foods. The connection between the two in the public's mind has little to do with genetic manipulation and everything to do with a lack of faith in policy makers. Not so long ago the government reassured the public that beef was safe. We now know that there was a risk of bovine spongiform encephalopathy, albeit very small. The public is right to be cynical and mistrustful.

We must ask why we need these foods when there are no obvious benefits to the population from their immediate introduction. The driving force behind genetically modified foods is neither need nor demand but certain multinational corporations. Thus, it is important to ensure that a desire to protect the public health-not the profits of multinational organisations-underpins all decisions on the introduction of genetically modified foods.

Emma Plugge Senior registrar in public health medicine

Buckinghamshire Health Authority, Verney House, Aylesbury HP19 3ET

emma.plugge@earthling.net

1 Dixon B. The paradoxes of genetically modified foods. BMJ 1999;318:547-8. (27 February.)

\section{Summary of electronic responses}

We received 12 rapid responses to Dixon's editorial $^{1}$ on our website. ${ }^{2}$ Only one defended genetic modification of food. "For thousands of years farmers have used crossbreeding to genetically engineer crops, mixing genetic material on a large scale. But now, when genetic mixing is performed on a tiny scale, it suddenly becomes unacceptable" (S Root).

In general, there was a sense of fear. "It is the question of crossing species' boundaries and that, as yet, we have no answer regarding the possible long term effects" (S Shropshire). Resistance to herbicides and pests might have unwarranted effects on the ecosystem and possibly also directly on health. "It cannot be assumed that crop resistance to pests is merely due to 'good genes.' These genes may well be responsible for chemicals produced by the plant that in themselves are responsible for the resistance" (J R Murray).

The subtitle to Dixon's editorial says that a climate of mistrust is obscuring the many different facets of genetic modification, and according to N Raithatha this is right: there seems to be scientific evidence that the public trust neither politicians nor scientists working for the government.

The higher motive for producing genetically modified food was also questioned. "Biotechnology companies ... want to use 
this technology primarily to make money" (A Dowd).

1 Dixon B. The paradoxes of genetically modified foods. $B M$ J 1999;318:547-8. (27 February.)

2 Electronic responses. Genetically modified foods. $e B M J$ 1999;318 (www.bmj.com/cgi/content/full/318/7183/547 \#responses).

\section{Preventing osteoporosis, falls, and fractures among elderly people}

\section{Few exercise programmes studied have prevented falls}

EDITOR-Kannus promotes physical activity for the prevention of injurious falls among elderly people. ${ }^{1}$ He acknowledges the uncertainty that surrounds the effectiveness of specific exercise programmes tested as interventions in randomised controlled trials. This is in contrast to the epidemiological evidence from longitudinal cohort or case-control studies. We agree with him that regular physical activity outside formal exercise programmes is likely to be beneficial to both younger and older people.

In developing evidence based guidelines for the prevention of falls in older people we found good evidence that exercise programmes for unselected older people living in the community do not prevent falls, ${ }^{2}$ with the possible exception of balance training (tai chi). ${ }^{3}$ Two trials found that selected older people (those aged over $80^{4}$ or with mild deficits in strength and balance ${ }^{5}$ ) benefit from individually tailored exercise programmes administered by qualified professionals. Our guidelines recommend that the implementation of exercise programmes for unselected older people should not be a priority.

By contrast, multifaceted intervention programmes, including the identification and treatment of postural hypotension, review of drug treatment, modification of the home environment, and possibly exercise training, do reduce the incidence of falls. Multiple risk assessment and modification have also proved successful in the context of an accident and emergency department. The main research challenge is to develop these interventions further and test them in pragmatic implementation trials rather than to search for the optimal exercise activity.

Gene Feder Senior lecturer

g.s.feder@mds.qmw.ac.uk

Yvonne Carter Professor

Sheila Donovan Facilitator

Department of General Practice and Primary Care, St Bartholomew's and the Royal London School of Medicine and Dentistry, Queen Mary and Westfield College, London E1 4NS

Colin Cryer Statistician

South East Institute of Public Health, King's

College London, Tunbridge Wells, Kent TN3 0XT

1 Kannus P. Preventing osteoporosis, falls, and fractures among elderly people. BMJ 1999;318:205-6. (23 March)

2 Feder G, Cryer C, Donovan S for the development oroup. Guidelines for the prevention of falls in older people. London: Queen Mary and Westfield College, 1998.

3 Wolf SL, Barnhart HX, Kutner NG, McNeely E, Coogler C,

$\mathrm{Xu}$ T, et al. Reducing frailty and falls in older persons: an investigation of tai chi and computerized balance training. JAm Geriatr Soc 1996;44:489-97.

Campbell AJ, Robertson MC, Gardner MM, Norton RN Tilyard MW, Buchner DM. Randomised controlled trial of a general practice programme of home based exercise to prevent falls in elderly women. $B M J$ 1997;315:1065-9.

5 Buchner DM, Cress ME, de Lateur BJ, Esselman PC, Margherita AJ, Price R, et al. The effect of strength and endurance training on gait, balance, fall risk, and health ervices use in com on gity-living older adults. $J$ Cemol 1997:52A:M218-24.

\section{Getting younger and older people moving may seem sensible, but evidence is lacking}

EDITOR-Kannus's editorial promoting lifelong physical activity as essential in preventing osteoporosis, falls, and fractures among elderly people is not evidence based. Several findings need to be considered.

Firstly, no randomised trials provide evidence that regular exercise reduces fractures.

Secondly, vigorous exercise during growth increases bone mineral density by $10-20 \%{ }^{2}$ and moderate exercise during growth also increases bone mineral density. ${ }^{3}$ But these benefits may be lost after activity is stopped. ${ }^{4}$ Although residual benefits in bone mineral density have been reported in retired athletes aged under 50 , falls and fractures are common in elderly people (those over 65$)$. Whether elderly people who were athletes or exercised moderately before retiring from sport have high bone mineral density is unknown.

Thirdly, most exercise intervention studies in adults report no change in bone mineral density or increases of 1-3\% (small changes of questionable biological significance given that the baseline bone mineral density is already low). One study suggests that exercise actually decreases bone mineral density.

Fourthly, the lower prevalence of past or current physical activity in patients with hip fracture than in controls is hypothesis generating, not hypothesis testing.

It may seem sensible to get "younger and older people moving," but evidence is lacking. How many fewer fractures would occur if lifelong exercise was widely taken up by younger and older people? Is the hypothesis one sided? Could lifelong exercise increase the risk of falls and fractures?

E Seeman Associate professor of medicine Austin and Repatriation Medical Centre, University of Melbourne, Melbourne, Australia ego@austin.unimelb.edu.au

1 Kannus P. Preventing osteoporosis, falls, and fracture among elderly people. $B M J$ 1999;318:205-6. (23 March.) 2 Bass S, Pearce G, Hendrich E, Delmas P, Bradney M, Harding A, et al. Exercise before puberty may confer residual benefits in bone density in adulthood: studies in active prepubertal and retired female gymnasts. J Bone active prepubertal and ret

3 Bradney M, Pearce G, Naughton G, Starke KS, Ehsani AA 3 Bradney M, Pearce G, Naughton G, Starke KS, Ehsani AA, Slatopolsky E, et al. Differing effects of moderate exercise boys. J Bone Miner Res 1998;13:1814-21.

4 Dalsky GP, Starke KS, Ehsani AA, Slatopolsky E, Lee WC, Birge SJ Jr. Weight-bearing exercise training and lumbar bone mineral content in postmenopausal women. $A n$ Intern Med 1988;108:824-8.

5 Rockwell JC, Sorensen AM, Baker S, Leahey D, Stock JL, Michaels J, et al. Weight training decreases vertebral bone density in premenopausal women: A prospective study. Clin

\section{Author's reply}

EDITOR-Feder et al emphasise that exercise in unselected groups of older people does not prevent falls while that in selected groups does. I do not know of any comparative study indicating which specific groups of older adults benefit from an exercise programme, but the randomised trials that have shown a benefit have included clearly different age groups, from a mean of $65^{1}$ to one of $84 .^{2}$ Thus age does not seem to be a strong predictor of success or failure of the programme. I personally believe that the programme's quality and the motivation of its leaders are crucial.

Feder et al point out that multifaceted intervention programmes can reduce falls in older adults. I agree. Tinetti et al and Close et al have provided strong evidence for this, ${ }^{3}$ Tinetti et al's study including balance and strengthening exercises. ${ }^{3}$ Unfortunately, neither study could separate the independent role of each of the modified factors, although such analyses are important. Thus these multifactorial interventions do not exclude exercise as one way of reducing the risk of falling.

Seeman is worried about the level of evidence concerning exercise in the prevention of osteoporosis and related fractures. As in any medical condition, few actions have been verified by randomised trials. This does not mean that we should stop trying to obtain better evidence, but at a certain point we have to summarise current knowledge and give recommendations. I agree that no randomised trial has proved that regular exercise reduces the risk of fracture; probably such a large and long trial will never be conducted successfully. This does not mean, however, that exercise is ineffective in preventing fractures related to age.

Many well controlled studies of physical activity and areal bone mineral density indicate that exercise during growing years is more beneficial than exercise in adulthood. What is now needed is long term follow up of those who once obtained clear bone gain by exercise in early life. The studies showing small increases in areal bone mineral density obtained by exercise in adulthood (1-3\%) may have underestimated the true effect of mechanical loading on bone strength. A recent experimental intervention showed that mechanical loading can improve bone strength by reshaping the bone structure without increasing its areal bone mineral density. ${ }^{5}$ If this finding is repeated the current pessimistic attitudes towards the possibilities of improving adults' bone strength with exercise must be re-evaluated.

The final answer to whether lifelong physical activity decreases the risk of falls and fractures will probably never be available, but the evidence summarised in my editorial speaks strongly for it.

Pekka Kannus Chief physician

Accident and Trauma Research Centre, UKK Institute, PO Box 30, FIN-33501 Tampere, Finland Klpeka@uta.fi 
1 McMurdo MET, Mole PA, Paterson CR. Controlled trial of weight bearing exercise in older women in relation to bone density and falls. BMJ 1997;314:569.

2 Campbell AJ, Robertson MC, Gardner MM, Norton RN, Tilyard MW, Buchner DM. Randomised controlled trial of a general practice programme of home based exercise to prevent falls in elderly women. $B M J$ 1997;315:1065-9.

3 Tinetti ME, Baker DI, McAvay G, Claus EB, Garrett P, Gottschalk M, et al. A multifactiroal intervention to reduce the risk of falling among elderly people living in the community. N Engl J Med 1994;331:821-7.

4 Close J, Ellis M, Hooper R, Glucksman E, Jackson S, Swift C. Prevention of falls in the elderly trial (PROFET): a randomised controlled trial. Lancet 1999;353:93-7.

5 Järvinen TLN, Kannus P, Sievänen H, Jolma P, Heinonen Aärvinen TLN, Kanninen M. Randomized controlled study of effects of A, Järvinen M. Randomized controlled study of effects of
sudden impact loading on rat femur. I Bone Miner Res sudden impact lo

*** A longer version of this letter is available on the $B M J$ 's website www.bmj.com

\section{Current census categories are not a good match for identity}

Editor-Pfeffer discusses the complexities of theories of race, ethnicity, and culture. ${ }^{1}$ Surveys in the United Kingdom (UK) rely on the census question that first appeared in the 1991 census (incorporating colour and country of origin ${ }^{2}$ ) to define ethnic groups. The Office of Management and Budget's classification is dominant in the United States. ${ }^{3}$ Does the menu of terms given to people included in such classifications offer a good choice? Using data from the south Tyneside heart study, ${ }^{4}$ we compared respondents' identification of their ethnicity using the census question, a description in an open question, country of birth, and country of family origin.

We recruited participants using the snowball sampling technique. ${ }^{4}$ Community workers provided the names and addresses of people aged 16-74 of South Asian origin who had been resident in South Tyneside for at least a year. (The term South Asian is used to refer to those individuals whose ancestral origin lies in the Indian subcontinent-here, India, Pakistan, and

Respondents' descriptions of their ethnic origin by 1991 census category (15 missing values). Figures are numbers (percentages)

\begin{tabular}{lcccc} 
& \multicolumn{5}{c}{ Ethnicity according to $\mathbf{1 9 9 1}$ census categories } \\
\cline { 2 - 5 } Self description & Indian & Pakistani & Bangladeshi & Other \\
\hline Indian & $81(62)$ & $2(5)$ & - & - \\
\hline British/English/Anglo Indian & $12(9)$ & - & - & $2(11)$ \\
\hline Indian Christian & $1(1)$ & - & - & - \\
\hline Kashmiri Indian & $1(1)$ & - & - & - \\
\hline Born in India but lived in Pakistan & $1(1)$ & - & - & - \\
\hline Pakistani & - & $29(67)$ & $1(1)$ & $1(5)$ \\
\hline Sikh & $12(9)$ & - & - & $5(26)$ \\
\hline British Sikh & $2(2)$ & - & - & $1(5)$ \\
\hline Indian Sikh & $2(2)$ & - & - & $1(5)$ \\
\hline Bangladeshi & - & $1(2)$ & $118(94)$ & - \\
\hline Bengali & - & - & $5(4)$ & - \\
\hline British Bengali & - & - & - & $1(5)$ \\
\hline Muslim & $1(1)$ & $2(5)$ & $1(1)$ & $1(5)$ \\
\hline Kashmiri Muslim & $2(2)$ & - & - & $1(5)$ \\
\hline British Muslim & - & $1(2)$ & - & - \\
\hline British & $6(5)$ & $5(12)$ & $1(1)$ & - \\
\hline British/English Asian & $4(3)$ & $3(7)$ & - & $5(26)$ \\
\hline Asian & $4(3)$ & - & - & $1(5)$ \\
\hline Black or Asian & $1(1)$ & - & - & $1(5)$ \\
\hline Total & $130(41)$ & $43(13)$ & $126(39)$ & $20(6)$ \\
\hline
\end{tabular}

Bangladesh-and includes those born in the UK and others migrating to the UK via a third country (for example, Kenya).)

Participants $(n=334)$ were interviewed by a trained interviewer using a structured questionnaire in the preferred language, usually in the participant's home. The respondents first chose one of the categories from the census question (white, black Caribbean, black African, black other, Indian, Pakistani, Bangladeshi, Chinese, and other), then provided a description of their ethnicity. They were also asked where they and their mother and father were born.

Nineteen self descriptions were given. The most striking observation was the rarity of the term Asian and the absence of the term South Asian-both commonly used in the UK to describe people originating from the Indian subcontinent. These labels do not capture ethnic identity. From the census categories, 39\% respondents chose Indian, 38\% Bangladeshi, 13\% Pakistani, 6\% other, and 1 black other (table 1). Only 81 (62\%) of those who were Indian on the census question described themselves as Indian when given the open choice.

There was less variation among those who chose Bangladeshi from the census categories. Altogether $74 \%$ of 27 respondents born in Pakistan described themselves as Pakistani, whereas only $56 \%$ of 93 born in India described themselves as Indian. Of 68 respondents born in the UK, $38 \%$ described themselves as Indian, 13\% as British/ English/Anglo Indian, and $10 \%$ as Sikh (table w1 on www.bmj.com). Self defined ethnic origin and country of family origin were highly related when the country of family origin was Bangladesh but less so when it was India or Pakistan (table w2 on www.bmj.com).

Using census categories is insufficient to capture self identification. If we had not asked the census question first there might have been even less agreement between modes of self identification. Too few categories are offered to reflect the true heterogeneity of ethnic groups. Similar issues also apply to other labels-for example, "black" and "white." Our analysis emphasises the need for fresh thinking if identity and self identification are to be the basis of ethnic grouping.

Judith Rankin Senior research associate Department of Epidemiology and Public Health, School of Health Sciences, Medical School, University of Newcastle, Newcastle upon Tyne NE2 4HH

J.M.Rankin@newcastle.ac.uk

Raj Bhopal Bruce and John Usher professor of public health

Department of Public Health Sciences, University of Edinburgh Medical School, Edinburgh EH8 9AG rbhopal@srvl.med.ed.ac.uk

1 Pfeffer N. Theories of race, ethnicity, and culture. BMJ 1998;317:1381-4. (14 November.)

2 Nazroo JY. The health of Britain's ethnic minorities: findings from a national survey. London: Policy Studies Institute, 1997

3 Bennett T. "Racial" and ethnic classification: two steps forward and one step back? Public Health Rep 1997;112 $477-80$.

4 Rankin J, Bhopal R, Wallace B. Factors influencing heart disease and diabetes in South Asians: the south Tyneside heart study. University of Newcastle upon Tyne: Department of Epidemiology and Public Health, 1997 . 5 Bhopal R, Donaldson L. White, European, Western, Caucasian, or what? Inappropriate labeling in research on race, ethnicity and health. Am J Public Health 1998;88:
1303-7.

**Additional tables are available on the BMJ's website www.bmj.com

\section{Importance of health} economics must be recognised when trials are designed

EDITOR-Barbert and Thompson's study is welcome if it leads trial designers to recognise health economics as more than a (non-essential) afterthought to their trial. ${ }^{1}$ The points that the authors make would benefit from a more complete understanding of the nature of economic data and the context in which economic analyses are undertaken.

Clinical outcomes in trials tend to be uni-dimensional and unambiguous (such as survival or response to treatment), whereas economic data are essentially multidimensional. Health care embraces the use of a multitude of resources, each measured in different units and attracting its own distinct pricing regime. The economic aspect of a typical clinical trial will require information to be collected for 20-30 such items, each subject to a different statistical distribution. Theoretically, sample size should be calculated for each of these and the trial's recruitment target determined as that of the largest. But this requires knowledge of the underlying distribution of each variableinformation that is rarely available-and so there is no reliable basis for sizing a trial other than from estimates of sample sizes for the clinical variables.

Assigning prices to resources consumed is difficult in the United Kingdom, where the cost of the same procedure can differ by 
fivefold or 10-fold between hospitals-as much from different accounting schemes as from local variations in true cost. Applying local prices to resources used in different hospitals can disguise the resource changes we are trying to detect, but applying some standard or average price renders the results unrepresentative of any location.

The problems inherent in health economic analyses are much more fundamental than those addressed by Barber and Thompson, which seem largely irrelevant at this stage in the development of the discipline. ${ }^{3}$ Sensitivity analysis is generally recognised to be the most effective way to address variability and uncertainty in an economic study, but even this must be used selectively, otherwise the wide range of feasible results generated renders the exercise uninterpretable. Perhaps the most practical advice is to concentrate on changes in the use of physical resources between competing arms of a trial. Local decision makers may then apply their own locally relevant cost weights to obtain meaningful cost per outcome ratios.

Health economics remains in its infancy. There is a long way to go before the statistical fine tuning suggested by Barber and Thompson outweighs more pressing priorities, not the least of which is that the resource requirements of trials should be given more than cursory attention at design time.

Alan Haycox Senior lecturer in health economics A.R.Haycox@liverpool.ac.uk

Adrian Bagust Senior research fellow

Tom Walley Director

Prescribing Research Group, Department of Pharmacology and Therapeutics, University of Liverpool

Competing interests: None declared.

1 Barber JA, Thompson SG. Analysis and interpretation of cost data in randomised controlled trials: review of published studies. BMJ 1998;317:1195-1200. (31 October.)

2 Fayers PM, Hand DJ. Generalisation from phase III clinical trials: survival, quality of life and health economics. Lance 1997;350:1025-7.

3 Haycox A, Drummond M, Wally T. Pharmacoeconomics: integrating economic evaluation into clinical trials. $\mathrm{Br}$ Clin Pharmacol 1997;43:559-62.

\section{Audit of use of ACE inhibitors and monitoring in general practice}

Guidelines on monitoring, on their own, are not sufficient

EDITOR-Kalra et al's paper describing an audit of monitoring renal function in general practice suggests that practice is often less than optimal, although associated with some uncertainty. ${ }^{1}$ Unfortunately, the authors do not give confidence intervals around their estimates of effect-which we provide here. The fact that only 34\% (95\% confidence interval $28 \%$ to $39 \%$ ) of practitioners checked renal function after initiating angiotensin converting enzyme inhibitors and $15 \%(11 \%$ to $19 \%)$ never checked it is an important finding. We disagree, however, with the authors' conclusion that producing guidelines on monitoring, on its own, will lead to an improvement in practice.

The authors state that renal monitoring has been neglected in recent guidelines and cite the North of England evidence based guidelines on the use of angiotensin converting enzyme inhibitors in primary care (to which we contributed) as an example of this. ${ }^{2}$ They recommend that "renal function should be checked before and 7-10 days after treatment is started in all patients and thereafter regularly (for example, annually) only in those with risk factors." Rather than neglect the issue of monitoring, the North of England Guidelines Group prioritised it. The Agency for Health Care Policy and Research also prioritised it in its guidelines on heart failure, ${ }^{3}$ on which this section of the North of England guidelines drew explicitly.

The North of England guidelines recommend that "before initiation of angiotensin converting enzyme inhibition ... [patients] should have their blood pressure, renal function, and serum potassium measured. These measurements should be repeated one week after initiation of treatment and again one week after each significant increase in dosage."” The guidelines go on to suggest monitoring of serum creatinine concentration at least annually in all patients and describe specific criteria for patients who develop renal insufficiency. Thus they actually propose monitoring standards more stringent than those suggested by Kalra et al, although it is acknowledged that no basis for recommending one monitoring period over another could be found. The evidence base is limited, although a recent small trial suggests that complications are rare. ${ }^{4}$

Merely publishing guidelines on monitoring seems insufficient if even those citing the guidelines do not recall the recommendations. More active strategies, perhaps through computerised reminders built into prescribing systems, are required; on the basis of Kalra et al's paper they should be developed with some urgency.

Nick Freemantle Senior research fellow

James Mason Senior research fellow

Medicines Evaluation Group, Centre for Health Economics, University of York, York YO10 5DD

Martin Eccles Professor of clinical effectiveness Centre for Health Services Research, University of Newcastle upon Tyne, Newcastle upon Tyne NE2 4AA

1 Kalra PA, Kumwenda M, MacDowall P, Roland MO. Questionnaire study and audit of use of angiotensin converting enzyme inhibitor and monitoring in general practice: the need for guidelines to prevent renal failure. BMJ need for guidelings

2 Eccles M, Freemantle N, Mason JM for the North of England ACE-inhibitor Guideline Group. North of England land ACE-inhibitor Guideline Group. North of England
evidence based development project: guideline for angioevidence based development project: guideline for angio-
tensin converting enzyme inhibitors in the primary care tensin converting enzyme inhibitors in the primary care management of adults with symptomatic heart failure
$B M J$ 1998;316:1369-75.

3 US Department of Health and Human Services, Public Health Service, Agency for Health Care Policy and Research. Heart failure: evaluation and care of patients with left-ventricular systolic dysfunction. Rockville, MD: US Department of Health and Human Services, 1994. (Clinical practice guideline 11.)

4 Lough M, Cleland J, Langan J, Cowley A, Wade A. Initiating angiotensin converting reuptake inhibitors mild to moderate heart failure in general practice: mild to moderate heart fill in 1352-3.

\section{Authors' reply}

EDITOR-Although awareness of the possibility of serious uraemic complications of angiotensin converting enzyme inhibitors dates back over a decade, ${ }^{1}$ we found that such complications are still frequently encountered in certain parts of the United Kingdom and are concerned by this.

Although non-evidence based recommendations for monitoring renal function are available, ${ }^{2}$ we are worried that one key area of monitoring is often neglected, both in the literature and by doctors supervising the care of patients receiving angiotensin converting enzyme inhibitors. This concerns patients who become highly dependent on their renin-angiotensin-aldosterone axis to maintain glomerular filtration because of an intercurrent illness or event (for example, an increase in diuretic dose) accompanied by renal hypoperfusion.

The most vulnerable patients are elderly patients with heart failure (and consequent baseline renal hypoperfusion) receiving diuretics who then have a common illness such as pneumonia, gastroenteritis, or even flu. ${ }^{3}$ These are the patients most likely to develop uraemia related to their angiotensin converting enzyme inhibitor and indeed are the group whom we see in the renal service. No current guidelines or recommendations emphasise the need to monitor these patients carefully at the time of their intercurrent illness; their renal dysfunction would not, therefore, be identified by the application of existing monitoring protocols.

As well as wishing to see this deficiency rectified by the development of an appropriate evidence based guideline we would echo Freemantle et al's call for more active strategies that would consolidate doctors' awareness of the need to monitor renal function more judiciously in their most vulnerable patients. Angiotensin converting enzyme inhibitors provide excellent benefits to many patients; more attention to monitoring renal function, with a consequent increase in doctors' confidence, might paradoxically lead to a desired increase in the use of these agents.

P A Kalra Consultant nephrologist Department of Renal Medicine, Hope Hospital, Salford M6 8HD phil@ren.srht.swest.nhs.uk

$\mathbf{P}$ MacDowall Specialist registrar in renal medicine Royal Preston Hospital, Preston PR2 9HT

M Kumwenda Associate specialist in nephrology Department of Renal Medicine, Glan Clwyd Hospital, Rhyl LL18 5UJ

M O Roland Director of research and development National Primary Care Research and Development Centre, University of Manchester, Manchester M13 6PL

1 Hricik DE, Browning PJ, Kopelman R, Goorno WE, Madias ME, Dzau VJ. Captopril-induced functional renal insufficiency in patients with bilateral renal-artery stenosis in a solitary kidney. N Engl J Med 1983;308:373-6.

2 Eccles M, Freemantle N, Mason JM for the North of England ACE-inhibitor Guideline Group. North of England evidence based development project: guideline for angiotensin converting enzyme inhibitors in the primary care management of adults with symptomatic heart failure. BMJ 1998:316:1369-75.

3 Textor SC. Renal failure relating to angiotensin-converting enzyme inhibitors. Semin Nephrol 1997;17:67-76. 


\section{Advice given to patients with fractures}

Drug treatments that reduce fracture rate are underused after vertebral fractures

EDITOR-We recently undertook a cost analysis of osteoporosis, which showed that the disease is probably more costly than earlier estimates quoted by Pal suggested. ${ }^{1}$ We estimated that the total annual cost of fractures in a United Kingdom population is around $£ 940$ million, with hip fractures costing roughly $£ 12000$ each. ${ }^{2}$ More importantly, using data from the general practice research database, like $\mathrm{Pal}$ we found little evidence that patients who had sustained a fracture were being offered treatment. ${ }^{3}$ The table (taken from our paper) summarises our results.

Number of patients receiving at least one prescription for drug that reduces fracture rate (HRT, calcium, vitamin D, bisphosphonate) in years before and after hip, wrist, or vertebral fracture $(n=100)$

\begin{tabular}{lccc} 
& \multicolumn{3}{c}{ Type of fracture } \\
\cline { 2 - 4 } & Hip & Wrist & Vertebral \\
\hline $\begin{array}{l}\text { Year before fracture } \\
\text { (1994) }\end{array}$ & 2 & 7 & 10 \\
\hline Year after fracture (1996) & 4 & 5 & 39 \\
\hline
\end{tabular}

HRT=Hormone replacement therapy.

In terms of evidenced based medicine the only population of patients that has been widely studied for secondary prevention is those who have sustained a vertebral fracture. Most, if not all, widely available treatments for the prevention of fractures have been shown to be effective at preventing new vertebral fractures in patients who have had one previously. Despite this, over three fifths of patients with a vertebral fracture diagnosed in primary care were not prescribed any drugs that reduce the fracture rate to prevent new vertebral fractures. Such patients are also at high risk of non-vertebral fractures. ${ }^{4}$ The priority in preventing fractures would seem to be to offer drug treatments that reduce the fracture rate to patients with existing vertebral fractures.

David J Torgerson Senior research fellow Centre for Health Economics, University of York, York YO10 5DD

djt6@york.ac.uk

Paul Dolan Senior lecturer in economics

Sheffield Health Economics Group and

Department of Economics, University of Sheffield, Sheffield S1 4DA

1 Pal B. Questionnaire survey of advice given to patients with fractures. BMJ 1999;418:500-1. (20 February.)

2 Dolan P, Torgerson DJ. The cost of treating osteoporotic fractures in the United Kingdom female population Osteoporosis Int 1999;8:611-7.

3 Torgerson DJ, Dolan P. Prescribing by general practitioner after an osteoporotic fracture. Ann Rheum Dis 1998:57: after an

4 Burger H, van Daele PLA, Algra D, Hofman A, Grobbee DE, Schütte HE, et al. Vertebral deformities as predictors of non-vertebral fractures. BMJ 1994:309:991-2.
Fragility fractures establish diagnosis of osteoporosis

EDITOR-Pal's short article highlights the lack of appropriate advice received by many patients with osteoporotic fracture, particularly those with hip fracture. ${ }^{1}$ Although comprehensive recommendations for the care of patients with hip fracture exist, ${ }^{12}$ it seems that they are not always implemented and opportunities for secondary prevention are missed. Measures that are effective in protecting against hip fracture include calcium and vitamin D supplementation and the use of hip protectors, ${ }^{3}{ }^{4}$ neither of which is routinely advised. In addition, many patients leave hospital without assessment of risk factors for falling, some of which, such as poor vision and environmental hazards, may be remediable.

The editorial accompanying Pal's article advocates dual energy $x$ ray absorptiometry in older patients with osteoporotic fracture, both to identify underlying osteoporosis and to provide a baseline for monitoring treatment. ${ }^{4}$ Although bone densitometry may sometimes be of value in confirming or refuting osteoporosis in individuals with a fracture, it is often unnecessary: the presence of a fragility fracture establishes a diagnosis of osteoporosis and is an independent risk factor for subsequent fracture.

A strong case can be made for treating patients with a fragility fracture, regardless of whether bone densitometry is available; this is particularly so for elderly patients with hip fracture, most of whom will satisfy the densitometric criteria for osteoporosis. Further justification for this approach is provided by the increasing evidence that safe and relatively short term interventions in elderly people can produce significant reductions in the fracture rate. ${ }^{34}$

The rationale for monitoring treatment can also be challenged. Response rates to antiresorptive treatment are generally reported as being greater than $90 \%$. Against this background it is difficult to understand why monitoring should be regarded as essential, particularly since the time required accurately to detect non-response may be three years or more

Finally, in view of the high prevalence of vitamin $\mathrm{D}$ deficiency in the elderly population, routine vitamin $\mathrm{D}$ supplementation would surely be a more cost effective approach to reducing hip fracture than measurement of serum 25-hydroxyvitamin D concentrations.

Juliet Compston University lecture

Department of Medicine, Addenbrooke's Hospital, Cambridge CB2 2QQ

jec1001@cam.ac.uk

I Pal R. Questionnaire survey of advice given to patient with fractures. BMJ 1991;318:500-1. (20 February.)

2 Royal College of Physicians. Fractured neck of femur: prevention and management. Summary and recommendtions of the report. J R Coll Phys Lond 1995;23:8-12.

3 Audit Commission. United they stand: co-ordinating care for elderly patients with hip fractures. London: HMSO, 1995.

4 Doube A. Managing osteoporosis in older people with fractures. BMJ 1999:318:477-8. (20 February.)

5 Compston JE. Vitamin deficiency: time for action. BMJ 1998;317:1466-7. (28 November.)

\section{Strategy to reformulate waiting} lists

\section{New Zealand has some suggestions for} NHS priority system for elective surgery

EDITOR-I have some suggestions that the BMA might like to consider when it designs the NHS priority system for elective surgery. ${ }^{1}$ My four suggestions are: use a scoring system instead of "banding" patients; don't use the words "severity score"-instead use "priority score"; include consumers in the groups for developing the priorities; and set up a booking system when you introduce priority assessment.

I recommend that patients are scored instead of banded because clinicians will be compelled to use the assessment tool to get a score (the alternative is to determine a category for the patient, based on the current clinical decision making). If you have to ration (determine to which level you can provide publicly funded operations) it is much easier to work with a scoring system as opposed to, for example, $25 \%$ of D category.

We have found that the assessment tool (and score) should reflect ability to benefit from surgery as well as "need" factors. If you use only severity as an indicator then all patients for day surgery will wait for a long time or miss out on their surgery. This, in fact, is a group who benefit greatly for each health dollar/pound spent on them, both directly and indirectly (days off work, quality of life, etc). To determine your priority assessment tool, please include consumers. Consumers are good at prioritising benefit and need and are essential to getting the community to "buy in" to the scheme and for transparency to priority setting.

Giving people an idea of when they will receive their treatment means changing the way that waiting lists are managed. The main impact in our system has been projecting out our surgical booking lists to six months. I don't think that you can introduce a priority assessment tool without looking at capacity and booking issues. If you start prioritising patients and give people certainty you need to be able to say, "Yes, we can carry out surgery on all of these people and the new patients expected each month within this time frame." If you are not able to do this then you have to determine the level to which you will be providing elective surgery.

Janine Cochrane Project leader for booking system. HealthCare Otago, Private Bag 1921, Dunedin, New Zealand

JanineC@HealthOtago.co.nz

1 Fricker J. BMA proposes strategy to reformulate waiting lists. BMJ 1999;318:78. (9 January.)

\section{Italy's public health system is changing} from waiting times to priority

EDITOR-Fricker reports that the BMA proposes a strategy to reformulate waiting lists in the United Kingdom. ${ }^{1}$ In the public health system, issues such as priority setting and appropriateness ratings in the referral of patients by general practitioners to specialists are usually faced in a hard (top down) 
way. Negative or positive lists exist or protocols are set up, commonly by insurance or government bodies, that have to be used by all professionals concerned.

In some areas of the Italian public health sector we are now experimenting with dealing with this matter in a soft (bottom up) way. General practitioners and specialists are called together to set up criteria for a simple priority model by specialty; each higher priority level contains more causes (and other clinical signs or facts) for referral, related to the consequences that delay of non-emergency care (diagnostic procedures in particular) would have.

Each priority level has its own space on the specialist timetable, and bookings are given by a booking centre, where staff have received full instruction on the procedures after common planned criteria in identifying the right level (and, consequently, the right time for the consultation) have been met. Specialists are asked to report if patients they checked were not appropriately booked, and monitoring of these reports gives the chance for remodelling and strengthening the model.

First results are positive, and the appropriateness of the referral system is improving quickly. A composite evaluation by specialists of 570 cases from the quoted surgeries was performed; in 67 of these cases the waiting time was considered to be delayed, in 53 cases it was early, and in 446 cases it was appropriate. (In the remaining four cases prescription was considered to be inappropriate.) We are now working with general practitioners to identify more clinical data able to define clinical categories with different levels of priority and to simplify the booking procedure; the general practitioner will define his or her prescription as priority $\mathrm{A}$ (or $\mathrm{B}$ or $\mathrm{C}$ or $\mathrm{D}$ ).

We will be able to identify major results as soon as the model starts in other areas of the Italian public health sector. We think that both an improvement in accessibility to healthcare services and a more effective allocation of the resources will be important consequences of this model.

Giuliano Mariotti Medical director Health Authority ULSS 2, 32032 Feltre, Italy mariotti@tqs.it

Rosanna Sommadossi Trained nurse

Booking Service, Health Authority APSS, 38100 Trento, Italy

Tommaso Langiano Medical director

Paediatric Hospital “Bambin Gesy," 00153 Rome, Italy

Roberto Raggi Public health consultant 47037 Rimini, Italy

1 Fricker J. BMA proposes strategy to reformulate waiting lists. BMJ 1999;318:78. (9 January.)

\section{Real-time priority scoring system must be used for prioritisation on waiting lists}

EDITOR-We would like to contribute to the debate in the $B M J$ about the role of prioritisation scoring systems ${ }^{1-3}$ and respond to the
BMA's recent discussion paper on this subject (which briefly mentions our work for a project initiated by the Welsh Office). ${ }^{4}$

Weale dismisses the possibility of providing an infinite variety of treatments to an infinite number of patients from finite resources. ${ }^{5}$ To channel the limited resources effectively, we have argued that the introduction of a clinical management tool incorporating a system of prioritisation based on the patient's degree of need is necessary. ${ }^{3}$ Workers at various centres throughout the world have investigated this problem without a clear consensus emerging. ${ }^{124}$ Prioritisation variables in common use are social handicap, morbidity, and disease.

Our elective algorithm incorporates these principles and introduces time in a proportionate and cumulative manner, adding the patient's derived priority score to an accumulating waiting list score each week The higher the need is scored the faster the progression through the list. Current guarantees in the patient's charter have been incorporated into the algorithm. An alternative algorithm incorporating the rate of progress of the condition, the ability of treatment to influence outcome, and the patient's level of pain and distress is used in patients with life threatening problems.

A computerised prioritisation system that changes with time allows more advanced analyses of the list, aiding effective management and resource allocation. The creation of a booking system is facilitated by prediction of admission dates. Potential breaches of the patient's charter can be predicted and patients diverted to other centres, or demand met with targeted resources.

The priority score for elective cases (termed the patient's initial quotient) is entered at the bottom of the waiting list. As it grows with time it is redefined as the patient's eligibility quotient, until the patient reaches the top of the list, at which point it is redefined as the patient's exit quotient. The summed total of patients' eligibility quotients, the average eligibility quotient, the mean exit quotient, and various other derivatives are amenable to analysis.

In our opinion the traditional method of analysing waiting lists, with its emphasis on maximum wait and patient numbers, is inadequate. Alternative concepts are needed when prioritising and managing waiting lists and resources. We believe that understanding waiting list dynamics will be possible only when a real-time priority scoring system is used.

B Davis Consultant otorhinolaryngologist S R Johnson Consultant trauma and orthopaedic surgeon

West Wales General Hospital, Carmarthen SE31 2AF

\footnotetext{
1 Kee F, McDonald P, Kirwan JR, Patterson CC, Love AHC. Urgency and priority in cardiac surgery: a clinica judgment analysis. $B M$ J 1998:316:925-9.

2 Hadorn DC, Holmes AC. The New Zealand priority criteria project. Part 1 Overview. BMJ 1997;314:131-4.

Davis B, Johnson S. Rationing health care. BMJ 1998 316:1092-3

4 BMA's Health Policy and Economic Research Unit Waiting list prioritisation scoring systems: a discussion paper. London: BMA, 1998.

5 Weale A. Rationing health care. BMJ 1998;316:410.
}

\section{Eligibility criteria improve children's access to long term ventilation at home}

EDITOR-Jardine et al comment that funding and home carers are common obstacles to discharge home for children on long term ventilation. ${ }^{1}$ Liverpool has a scheme which largely overcomes these obstacles.

Liverpool Health Authority and the local authority have agreed on eligibility criteria for joint funding for children with complex needs, which has removed the delay previously caused by funding negotiations. The eligibility criteria are based on a discussion document produced in $1994^{2}$ which aims to define childhood disability by producing a functional grade of severity. Impairment of function is assessed in 10 categories that cover mobility, sensory impairment, physical health, learning, and personal care. We have added an 11th category, vulnerability, to include technology dependent children such as those on long term ventilation. Children who meet the jointly agreed criteria are eligible for joint funding split equally between social services and the health authority for a home care package, or three ways with the education department if the package includes school support.

The joint funding scheme has been in existence for 18 months. We have had two new children on long term ventilation during this time. It took 6 weeks after initial referral for the health authority to confirm joint funding with social services, with a further 4 weeks for an additional educational agreement to funding for one child.

Home care is provided by lay carers supported by a qualified paediatric nurse. The carers are employed by the Royal Liverpool Children's (NHS) Trust, which is responsible for recruitment, training, and supervision. Training is patient specific and is delivered both in hospital and at home by the support nurse, assisted by high dependency unit and special school nursing staff. The main delay in the process is recruitment and training of carers, with a minimum training period of 6 weeks.

We currently have three children in Liverpool on long term ventilation at home, supported by 10 carers. The annual cost is $£ 108000$, which covers the care packages but not the capital cost of equipment. We have estimated, based on experience over the past 6 years, that there will be two new children a year requiring long term ventilation at home.

Sian Snelling Consultant community paediatrician Alder Hey Children's Hospital, Liverpool L12 2AP

\footnotetext{
1 Jardine E, O'Toole M, Paton JY, Wallace C. Current status of long term ventilation of children in the United Kingdom: questionnaire survey. BMJ 1999:318:295-9. (30 January.)

2 British Association for Community Child Health. Disability in childhood; towards nationally useful definitions. London:
} BACCH, 1994. 


\section{Maybe the time has come for the primacy of the patient in the NHS}

EDITOR-We wholeheartedly agree with Hampton's statement that cooperation and understanding between primary and secondary care are crucial. ${ }^{1}$ Unfortunately, his article has done little to promote these. $\mathrm{He}$ states that there is "no evidence that an NHS based on the primacy of primary care will function any better" and then attacks primary care with equally little evidence in support of his uninformed, dogmatic statements.

Firstly, the increase in admissions for medical emergencies does not prove that general practitioners are increasingly seeing the importance of secondary care. It does, however, correspond with the evidence that patients are consulting their general practitioners more often, ${ }^{2}$ that the population is older and better educated, and that general practitioners are more aware of the technical support that can be provided only in larger centres.

Secondly, there is no evidence that an emphasis on primary care will inevitably slow medical advance. Hampton points out rightly that secondary care is responsible for most evidence based practice; this is surely a wonderful argument for putting more resources into general practice research, since $70-90 \%$ of patient contact occurs in primary care.

Thirdly, primary care rightly emphasises common conditions. When did rare and difficult problems become the "important" illnesses? Surely this is not the view of patients, who are more likely to have really important illnesses such as ischaemic heart disease, depression, and back pain. Prevention has been proved to reduce mortality (for example, the Scandinavian simvastatin survival study ${ }^{3}$ ) and is also rightly emphasised.

Finally, the statement that the "treatment of important illnesses should be the first priority" in medical education will be surprising to those who have read the General Medical Council's recommendations for such education. ${ }^{4}$ A new generation of doctors is being trained to undertake and value prevention of disease, the importance of common illnesses, and, most importantly, cooperation and mutual respect across primary and secondary care.

One classic example of cooperation is the management of diabetes mellitus. Monitoring of diabetes can be done equally effectively in primary and secondary care, ${ }^{5}$ but the answer is not competition but cooperation, with professionals acting as districtwide teams. The primary factor, and the deciding factor, must be the patient. Has the time come for the patient led NHS and the primacy of the patient?

Hugh Alberti Lecturer in primary health care Grey Towers Court, Middlesbrough TS7 0NJ Hugh@lone.demon.co.uk
George Alberti President

Royal College of Physicians of London, London NW1 4LE

1 Hampton JR. The primacy of primary care. BMJ 1998;317:1724-5. (19-26 December.)

2 Office of Health Economics. 10th compendium of healt statistics. London: OHE, 1997.

Scandinavian Simvastatin Survival Study Group. Randomised trial of cholesterol lowering in 4444 patients with coronary heart disease. Lancet 1994;344:1383-9.

4 General Medical Council. Tomorrow's doctors: recommendations on undergraduate medical education. London: GMC 1993.

5 Griffin S. Diabetes care in general practice: meta-analysi of randomised controlled trials. BMJ 1998;317:390-6.

\section{Edinburgh college's consensus statements are not purely for UK}

EDIToR-As organisers of the Royal College of Physicians of Edinburgh's consensus conference in medical management of stroke, we would like to comment on some points that Bogousslavsky raises in his editorial.

The Edinburgh consensus statement had the "flavour of UK practice" because it was primarily directed at medical practice in the UK. Accordingly, the consensus panel was selected from within the UK, although it considered evidence that was international and collated through reviews (from, for example, the Cochrane Collaboration), which were circulated as background papers. Furthermore, the conference had international speakers, was advertised internationally, and welcomed international delegates. Finally, the consensus statement was offered to relevant international journals.

An account of the development and methodology of the Edinburgh consensus conferences will be published later this year in the college proceedings. The other consensus statements and guidelines that Bogousslavsky refers to should likewise be examined for their methodological development, the representativeness of their authors, and their intended audience.

In keeping with the traditions and mission statement of this college, its consensus conferences are primarily for the UK but offered to the world for debate. As Bogousslavsky notes, their consensus statements are simple but not simplistic; this is deliberate in order to provide guidance for all people involved in stroke managementboth those who are and those who are not experts. As healthcare systems around the world vary so widely, it seems unlikely that a single consensus statement would be applicable to all countries.

We acknowledge that for antiplatelet treatment both lower and higher doses of aspirin than that recommended in the statement $(75-300 \mathrm{mg} /$ day) are given. However, the only evidence for efficacy in acute stroke is for doses within this range, and such doses also have proved efficacy in secondary prevention. Evidence suggests that both modified release dipyridamole and clopidogrel are acceptable alternatives in patients with stroke or transient ischaemic attack who are intolerant of aspirin, ${ }^{3}$ and dipyridamole is cheaper.
We acknowledge that thrombolytic treatment in acute stroke is controversial because its risk-benefit ratio is uncertain. The Edinburgh consensus panel therefore thought that further randomised trials were required before it could be recommended in routine medical management. $B M J$ readers will doubtless wish to review the evidence before deciding whether to be guided by consensus panels or by "fulminating leading experts on both sides of the Atlantic."

Martin Dennis Reader in stroke medicine Margaret Farquhar College consensus conference organiser

Peter Langhorne Senior lecturer in geriatric medicine Gordon Lowe College assessor

Charles Warlow Professor of neurology

Royal College of Physicians of Edinburgh,

Edinburgh EH2 1LQ

1 Royal College of Physicians of Edinburgh. Consensus conference on medical management of stroke: consensus statement. Proc R Coll Physicians Edinb 1998:28:367-9.

2 Bogousslavsky J. Consensus in stroke management? BMJ 1999;318:140-1. (16 January.)

3 Diener HC, Cunha L, Forbes C, Sirenius J, Smets P, Lowenthal A. Dipyridamole and acetyl salicylic acid in the secondary prevention of stroke. European Stroke Prevention Study (2) Group. J Neurol Sci 1996;143:1-13.

4 Caprie Steering Committee. A randomised, blinded, trial Caprie Steering Committee. A randomised, blinded, trial
of clopidogrel versus aspirin in patients at risk of of clopidogrel versus aspirin in patients at risk
ischaemic events (CAPRIE). Lancet 1996;348:1329-39.

\section{South Africa must admit that HIV/AIDS is its greatest enemy}

EDITOR-Schuklenk is wrong in stating that the price that Glaxo-Wellcome demands for zidovudine is too high for South Africa to treat pregnant women infected with HIV. ${ }^{1}$ In truth, Glaxo-Wellcome has set a standard for industry cooperation with developing countries by making zidovudine available to South Africa at a cost three quarters below that in Western countries for the prevention of perinatal transmission of HIV.

The company is correct to expect that the government should be prepared to purchase the drug at a minimal rate. The argument that South Africa cannot afford this reduced cost of zidovudine is nonsensical if one considers that the drug would be used only for relatively short periods toward the end of pregnancy and that the government has just invested many millions of dollars on the purchase of fighter aircraft for its armed forces.

The real problem in South Africa is the government's continuing failure to admit that HIV/AIDS is its greatest enemy and to devote necessary resources to limiting the spread of HIV.

Mark A Wainberg President, International AIDS Society

McGill AIDS Centre, Montreal, Canada mdwa@musica.mcgill.ca

1 Schuklenk U. South African government's response to AIDS crisis is sound. BMJ 1999;318:1143. (24 April.)

\section{Rapid responses} $e B M$

Rapid responses submitted directly to our website are available on www.bmj.com 